\title{
Research on the Teaching Strategy of Middle School Chemistry Under the Concept of Wisdom Education
}

\author{
Chen Min*, Tang Ren Ju, Liao Jia Li, Yang Xi Mei \\ College of Computer and Information Science, Chongqing Normal University, Chongqing, China

\section{Email address:} \\ 1358516383@qq.com (Chen Min),1508063309@qq.com (Tang Ren Jun), 1134970980@qq.com (Liao Jia Li), \\ yxm1601@126.com (Yang Xi Mei) \\ ${ }^{*}$ Corresponding author
}

\section{To cite this article:}

Chen Min, Tang Ren Ju, Liao Jia Li, Yang Xi Mei. Research on the Teaching Strategy of Middle School Chemistry Under the Concept of Wisdom Education. Science Innovation Vol. 9, No. 3, 2021, pp. 107-113. doi: 10.11648/j.si.20210903.16

Received: April 2, 2021; Accepted: May 10, 2021; Published: May 24, 2021

\begin{abstract}
In the 21st century of the information age, the rapid progress and development of computer and information technology have brought about the innovation of educational technology, and some advanced teaching methods have emerged accordingly. The traditional teaching mode needs to be gradually transformed to the intelligent teaching mode. Chemistry is an important subject in middle school. The traditional chemistry classroom can not meet the requirements of new curriculum reform and quality education. In this paper, the concept, background and connotation of intelligent education were sorted out, keywords were extracted by BICOMB and SPSS25.0 software, and the research trend of intelligent education was statistically analyzed. Based on the concept of intelligent education, the teaching strategies of middle school chemistry were proposed: showing the independent learning list, cultivating the ability of personalized independent learning; Optimize problem scenarios to stimulate learning motivation; Network platform interaction, active classroom atmosphere, mobilize the enthusiasm of students; Using Internet technology to regulate experimental teaching; Complete tasks online and teach students according to their aptitude. Use educational games and comprehensive review to consolidate knowledge. Improve the quality of chemistry classroom teaching.
\end{abstract}

Keywords: Wisdom Education, Chemistry Teaching, Middle School Chemistry, Teaching Strategy

\section{智慧教育理念下中学化学的教学策略研究}

陈敏", 唐仁菊, 廖家利, 杨喜梅

重庆师范大学计算机与信息科学学院, 重庆, 中国

\section{邮箱}

1358516383@qq.com（陈敏）, 1508063309@qq.com（唐仁菊）, 1134970980@qq.com（廖家利）,yxm1601@126.com（杨喜梅）

摘要：在信息时代的 21 世纪, 计算机和信息技术迅速进步和发展, 带来了教育技术的创新, 一些先进教学手段随之出 现, 传统的教学模式需要逐渐转向智慧型教学模式。化学是中学的一门重要学科, 传统的化学课堂已不能适应新课改 和素质教育的要求。本文梳理了智慧教育的概念、背景以及内涵, 利用BICOMB和SPSS25.0软件对关键词进行提取、 统计分析智慧教育的研究趋势, 并基于智慧教育理念提出中学化学教学策略: 展示自主学习题单, 培养个性化独立学 习能力; 优化问题情景, 激发学习动机; 网络平台互动, 活跃课堂氛围、调动学生积极性; 利用互联网技术, 规范实 验教学; 线上完成任务, 因材施教; 使用教育游戏, 综合复习巩固知识。提高化学课堂教学质量。

关键词: 智慧教育, 化学教学, 中学化学, 教学策略 


\section{1. 引言}

IBM提出智慧地球战略，2008年在《智慧地球：下一 代领导议程》中首次提出了智慧地球的概念, 当 “智慧地球” 思想冲击到不同领域时, 新的思想随之迸出 [1], 智慧教育 便是其中之一。教育作为信息化发展的重要部分, 随着教 育信息化进程加快, 并且逐步融入智慧教育领域, 全面推 动了目前社会信息化的进程[2]。以智慧教育引领教育信息 化的创新发展 [3]。

教育部发布的文件《教育信息化2.0行动计划》中提 到, 智慧教育作为信息技术赋能的未来教育范式, 被给予 很高的期待, 其创新发展更是成为新时代教育信息化八大 实施行动之一 [4]。当前, 现代计算机技术已广泛应用于课 堂教学 [5]。课堂教学中引入智慧教育是素质教育的需要、 教育改革的需要、学校发展的需要 [6], 培养创新型人才, 是当前的研究热点。

随着国家对智慧教育观念的改变, 智慧教学成为教育 的主导模式, 促进信息技术与课堂教学的有效整合。化学, 作为中学一门实用性、探究性高的学科, 在传统化学课堂 中存在的问题急需解决。对于教师而言, 仅仅是对智慧教 育的理论研究是远远不够的, 关键在于教学中如何实现与 现代化信息技术相结合, 即智慧教育的实际应用。因此, 如何让智慧教育与中学化学教学很好的结合, 使课堂教学 获得更好的教学效果, 是本文的研究重点。

\section{2. 智慧教育的概述与发展}

\section{1. 智慧教育的概述}

智慧教育作为教育信息化的高端形式, 在世界范围内 受到越来越多的需求和影响 [7]。关于智慧教育的思想, 早
先是由哲学家提出并阐述的, 随后, 智慧教育受到了国内 外各界学者的关注。但是, 国内外对智慧教育的系统研究 还比较少。

信息化环境下的智慧教育, 可追溯到1997年钱学森先 生提出的“大成智慧学”。 IBM的智慧地球战略是推进智慧 教育最具有影响力的国际事件 $[2,8]$, “智慧教育”一词便源 于此。之后, 国内外学者将这个理念应用于教育, 便发展 了智慧教育的概念。我国学者靖国平认为:传统意义上智 慧教育的理解具有一定的局限性, 广义智慧教育是一种更 为全面、丰富、多元、综合的智慧教育, 它主要包含着三 个既相互区分又彼此联系的方面，即理性（求知求真）智 慧的教育、价值 (求善求美) 智慧的教育和实践（求实求 行）智慧的教育 [8]。

智慧教育的概念存在多种表述，可归纳为“为智慧存 在而教育”和“以智慧方式来教育”[9]。总体而言, 智慧教 育理念是利用多媒体、互联网实现教学资源、信息资源和 智力资源的共享和传播, 形成一种开放、高效的教学模式 [10]。智慧教育强调智能技术与教学的结合, 构建智慧学 习系统, 创设智慧型学习评价、创设新的教学模式以及新 的学习理论[11], 激发学生对学习的兴趣, 以学生为中心, 以培养创新型人才为目标。

\section{2. 智慧教育的发展}

\subsection{1. 年度分析}

依据知网检索“智慧教育”统计中文发文量, 按年份进 行分类。本文选取2005年之后的发文量进行统计, 结果如 图1所示:

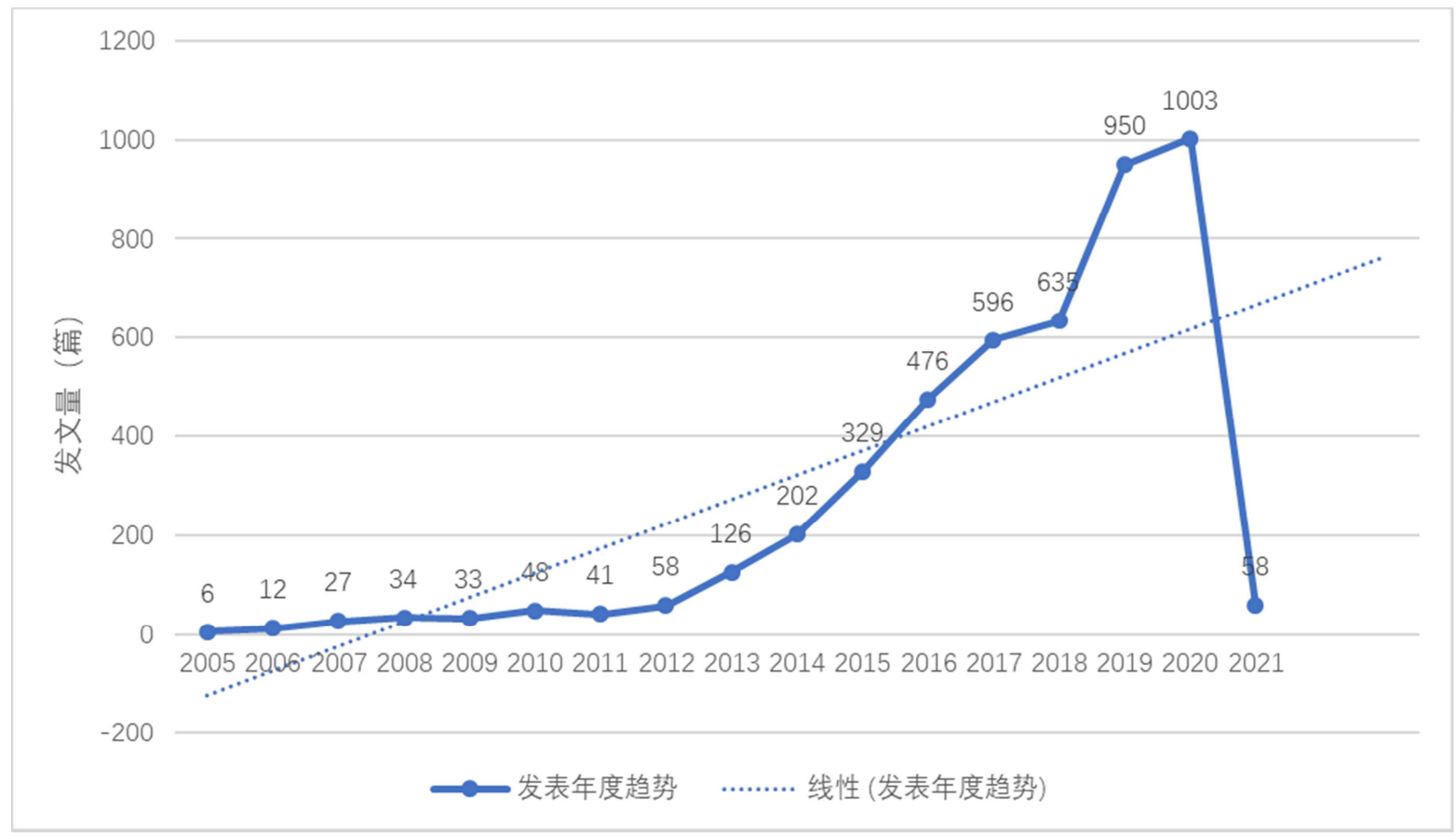

图1 智慧教育在我国的研究论文数量以及发展趋势。 
根据统计可知, 智慧教育在我国起步较晚, 2005年之前, 极少有关于智慧教育的论文发表, 从2005年开始, 关于智慧 教育的论文数量开始上升, 学术界对于智慧教育的研究热度 有了显著的变化。近十年间的文献数量总体呈上升趋势。从 图中可以看出, 智慧教育在我国的未来发展趋势上升的, 将 会继续被关注与研究，论文的发表数量会持续增加。

\subsection{2. 研究热点分析}

更准确的了解某领域目前的发展趋势, 需要对关键词 进行提取分析。数据来源于知网2015年-2020年的学术期
刊，包括SCI来源期刊、北大核心、CSSCI，以“智慧教育” 为主题进行精确检索, 最后共得到 465 篇样本文献, 并选 择自定义格式导出。

依据BICOMB2.01统计这些文献的关键词。将导出的 TXT文档导入BICOMB软件进行关键词提取, 篮选词频大 于等于 10 的关键词生成词篇矩阵、共现矩阵, 导出共现矩 阵, 导入SPSS 25.0软件进行系统聚类分析, 得到如图2所 示的聚类树状图。

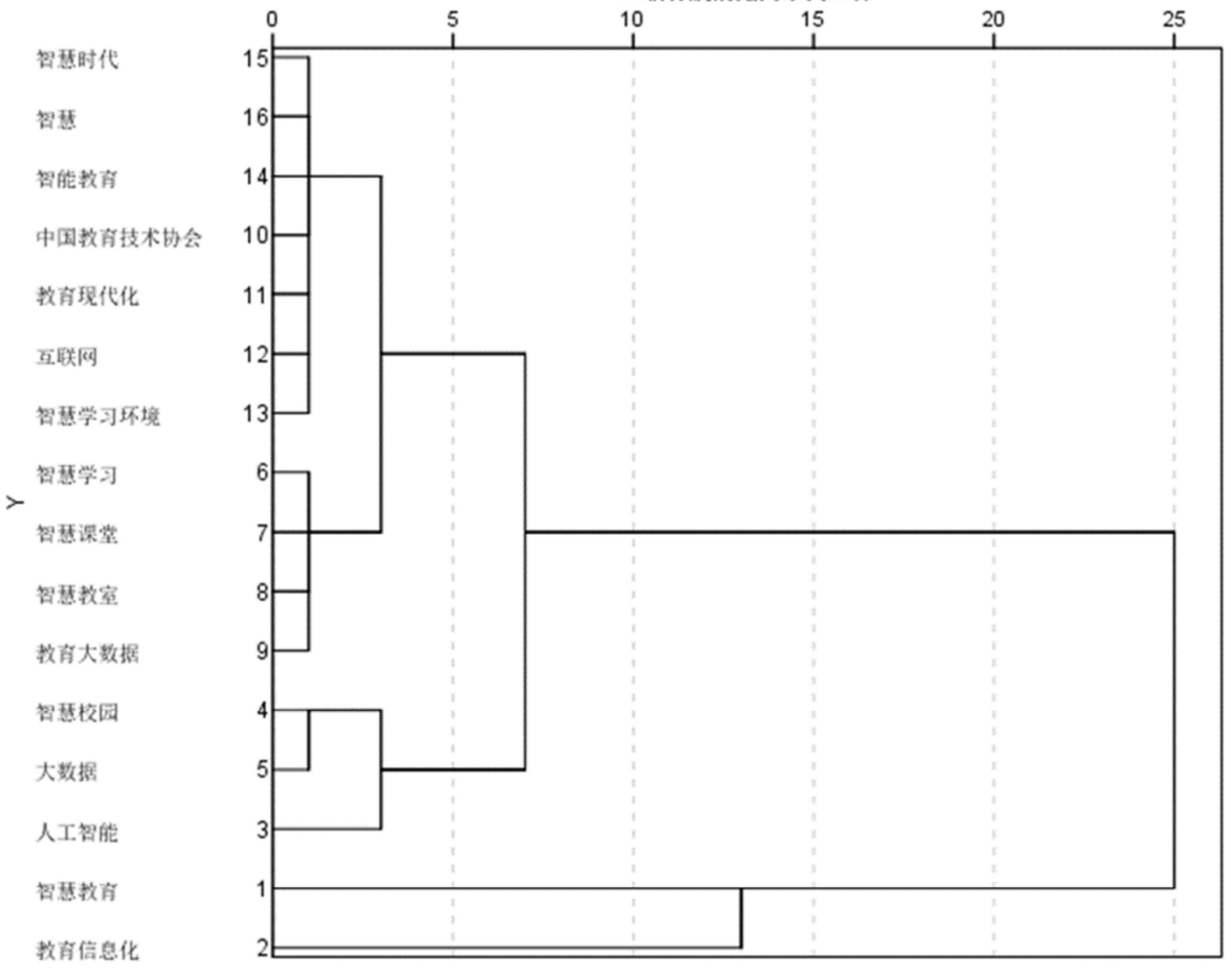

图2 智慧教育研究关键词聚类图。

聚类结果如表 1 所示, 由聚类分析将主题词分为四个 类别, 类别一主要研究方向是教育大数据与智慧教育相结 合, 在教学中的应用综述研究; 类别二是大数据与人工智

\section{使用沃德联接的诽系图}

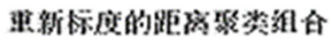
$10 \quad 15$ $1 \quad 20 \quad 25$ 能视野下的智慧教育研究; 类别三、类别四是对于智慧教 育本身的理论研究;

表1 智慧教育研究关键词聚类表.

\begin{tabular}{ll}
\hline 类别 & 聚类分析 \\
\hline 类别一 & 智慧学习、智慧课堂、智慧教室、教育大数据、中国教育技术协会、教育现代化、互联网、智慧学习环境、智能教育、智慧时代、 \\
类别二 & 智慧 \\
类别三 & 智慧教育 \\
类别四 & 教育信息化 \\
\hline
\end{tabular}


近年来, 智慧教育的主要研究内容表现在将智慧教育 与学校教育相结合, 由理念向实践迈进。据相关研究表明, 当前关于智慧教育理论研究方面相对丰富, 实践方面研究 较少。传统课堂已不能满足学生的学习需求, 我们应该更 加努力的研究适合于不同学科的不同教学策略, 教师借助 智慧教育来帮助学生构建出完整的智慧体系, 使学生能发 现自身的智慧并且善于利用[12]。

\section{3. 智慧教育与中学化学教学结合}

\section{1. 智慧教育在中学化学教学的研究现状}

当前初中化学教学中, 为达到教学进度及教学目标, 让学生能够应对各种考试, 仍然有一些教师受传统教学观
念的影响, 在教学过程中仍然以教师讲解为主, 学生被动 接受, 课堂交流互动较少。

目前智慧教育的相关理念的研究在逐年增多, 但将 智慧教育理念引入中学化学的研究相对比较少 [13]。通 过知网数据统计, 如图3所示, 智慧教育在化学方面的 研究主要从2013年才开始, 到目前为止, 知网检索关键 词: 智慧教育\&化学, 文献数量较少, 且实践方面的研 究较少。虽然尚处于发展阶段, 但整体发展趋势是上升 的, 会在发展需要、技术发展、政策推广下越走越远 $[6,14]$ 。

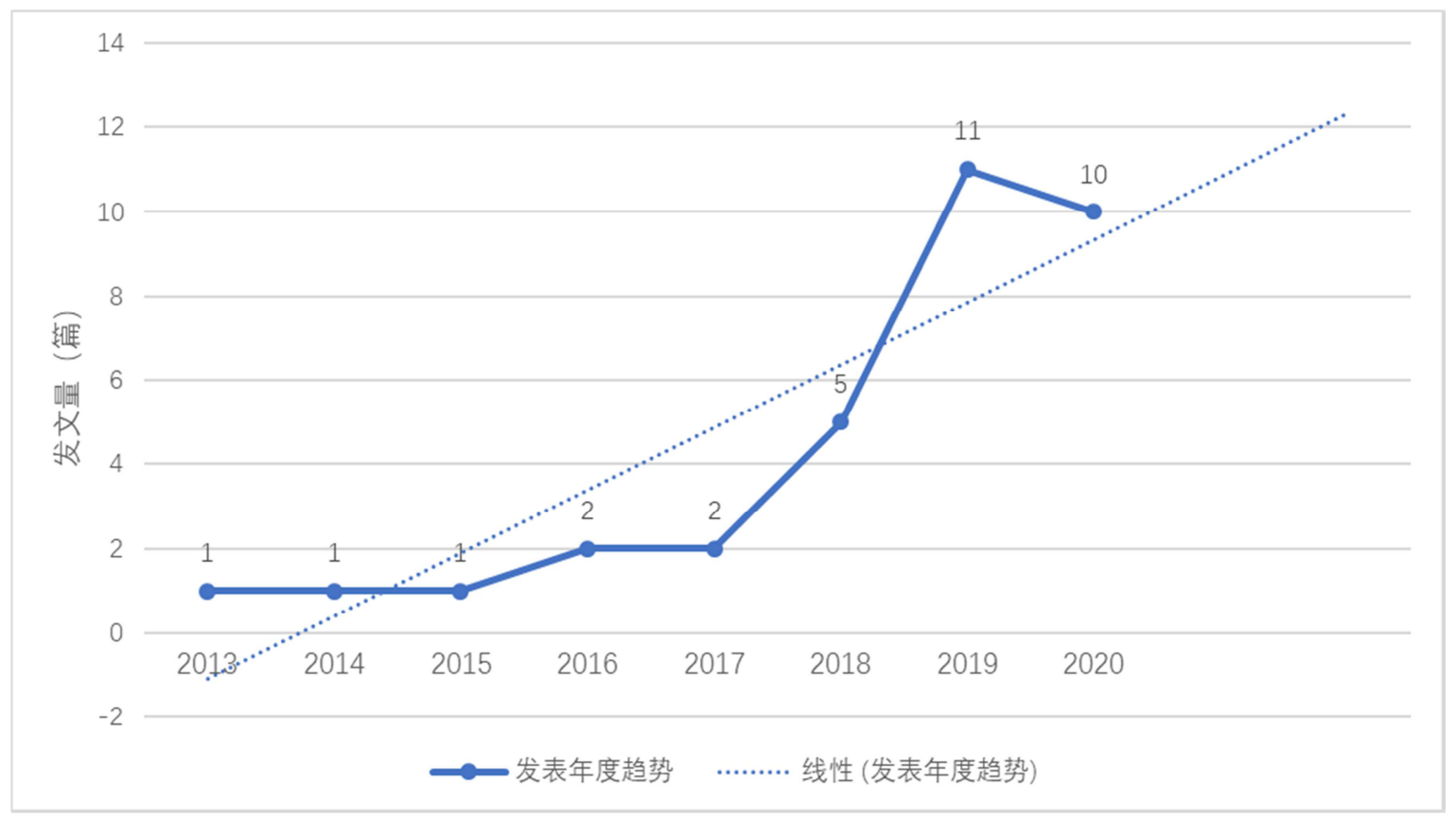

图3 智慧教育在化学方面的研究论文数量以及发展趋势。

\section{2. 智慧教育在中学化学教学的契合性}

在传统的化学教学课堂中, 大部分课堂是教师讲授, 学生听讲。智慧教育的理念认为, 课堂已不再是传统意义 上的知识传授型课堂, 更多是基于信息技术的知识分享型、 智慧型课堂 $[14]$ 。

\subsection{1. 智慧教育为中学化学教学提供趣味性}

传统中学化学课堂学习中, 学生学习的整个过程是索 然无味的。引入智慧教育, 利用多媒体和网络技术激发学 生的学习兴趣, 使学生更加积极的投入到化学内容的学习 中, 提高教学效果。

\subsection{2. 智慧教育为中学化学教学提供实验可操作性}

化学这门课程的很多内容是抽象的、以实验为主, 教 学环境有限且考虑到危险系数的问题, 导致很多化学实验 无法进行, 教师很难挖掘这门课程的兴趣, 学生学习兴趣
和积极性低下。且面对教育改革, 化学教学必须更多的借 助现代教育技术来改进课堂教学, 全面培养学生化学素养, 提高课堂质量。

\subsection{3. 智慧教育为中学化学教学提供情境性}

学生在学习中学化学时, 会遇到许多各种各样的记忆 材料, 例如符号等。将智慧教育与化学教学相结合, 将抽 象的概念形象化、清晰化, 学生可以身临其境的直接感受, 加深印象, 能够快速清晰的记住相关知识。

\subsection{4. 智慧教育与中学化学教学结合的可接受性}

根据调查显示, 学生也乐于接受这种新型的教育模式, 智慧教育理念下的化学课堂变得生动丰富起来, 学生的思 维更加活跃、操作能力变强, 学习效果得到提高。因此, 将智慧教育与中学化学教学整合对提高教学效果具有很 大影响。 


\section{4. 智慧教育理念下中学化学教学的教学策略}

智慧教育理念, 就是以学生为中心, 让学生可以主动 学习、根据自己的需要、按照适合自己的学习方式学习。
智慧教育可以应用于中学化学教学的各个阶段, 也可以应 用到不同化学知识的学习中。依据传统教学模式, 结合智 慧教育理念, 设计了多个课堂教学步骤的化学智慧教育策 略, 如图4所示。

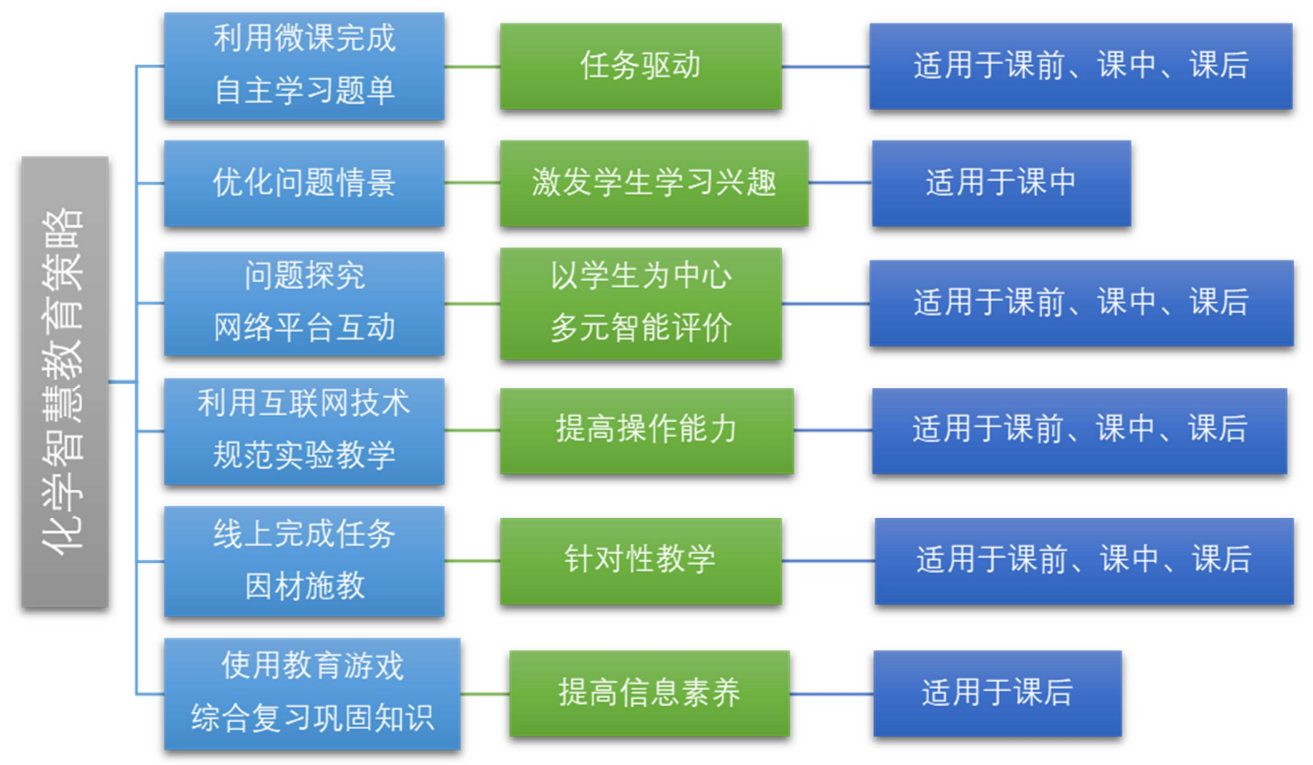

图4 化学智慧教育策略。

\section{1. 展示自主学习题单, 培养个性化独立学习能力}

任何一个学生都是独立的个体、都是与众不同的, 对 于课堂知识的学习效果也是不同的。在中学阶段, 学生学 习的知识很广, 很多老师会加快教学进度。这种教学模式 会增加学生的压力、降低教学效率。所以在教学过程中采 用任务驱动学生完成自主学习的任务, 学生根据自身的情 况进行自主学习, 培养个性化独立学习的能力。

在智慧教育理念下使用翻转课堂进行化学教学, 依赖 大数据、学习分析等数据对学习结果进行统计分析。我们 可以把教材的知识点进行梳理, 整合网络资源、教学重难 点, 做成微视频放在教学平台上, 学生根据自主学习任务, 以及自己的实际情况选择微课进行课程预习、学习或复习, 突破重难点, 方便学生查漏补缺, 促进学生个性化独立学 习, 提高学习质量。教师在教学过程中需要因材施教, 所 以教师需要从不同的视角开展教学, 微课就可以很好的改 变传统课堂教学视角单一的情况。除此之外, 学生可以在 讨论区进行交流讨论, 相互学习。

\section{2. 优化问题情景, 激发学习动机}

兴趣是最好的教师，苏霍姆林斯基说过：“在人的心 灵深处, 都有一种根深蒂固的需要, 这就是希望自己是一 个发现者、探究者、探索者, 而在儿童的精神世界里中这 种需要特别强烈”[15]。利用现代信息技术辅助中学化学课 堂, 使教学内容生动形象, 激发学生的学习兴趣, 使学生 在生动愉快的氛围中学习, 学生的学习动机增强, 教学效 果则更好。

在教学过程中, 教师可以借助多媒体、互联网技术, 构建化学智慧课堂, 充分利用化学教学资源, 将化学知识
实际化, 在此基础之上来学习化学知识。例如相关概念、 原理等的学习, 教师可设置网络小游戏来激发学生的求知 欲, 同时可以结合视频等多媒体设备来让学生在实际生活 场景中边听边看边思考, 让学生体会到化学与生活的联系。 例如讲解原子、分子等微观粒子的一些抽象概念的时候, 采用电脑模拟, 将抽象过程变成可视化过程, 结合教师的 讲解, 学生理解更加深刻。

\section{3. 网络平台互动, 活跃课堂氛围、调动学生积极性}

智慧教育理念要求以学生为中心, 传统课堂教学中学 生的参与度不高, 获取资料的渠道单一, 在智慧教育理念 下, 网络平台的使用让课堂教学形式多样化、评价方式多 元化, 学生的积极性增强。教师可以根据互动过程掌握学 生对知识点的理解情况。

采用“云十端”的学习方式, 通过平台互动的形式, 学 生之间可以相互评价, 教师终端可以实时查看学生的答题 情况, 统计准确率等信息并呈现在大屏幕上, 可以调动学 生的竞争欲望，激发学生思考问题的能力。同时教师可以 从学生的答案中找到具有代表性的答案进行讲评, 课堂效 率得到的很大程度的提高。

例如在学习《酸碱中和反应》一课中, 学生在设计实 验方案的时, 有不同的设计思路, 教师可以查看学生的实 验设计方案, 学生可以通过平台分享自己的设计方案, 同 学之间互相评价、讨论, 形成多元智能评价, 从而进一步 思考、完善, 教师再进行点评讲解。

\section{4. 利用互联网技术, 规范实验教学}

化学是以实验为基础的学科。由于许多学校的教学条 件有限, 化学实验很难进行, 基本上是以教师讲解、演示, 
学生参与较少。教师在培养学生良好的行为习惯、严谨的 科学态度、牢固的安全意识等方面遇到了巨大的挑战[16]。 在智慧教育理念下, 学生可以根据教师的讲解, 以及在选 定的智慧教育平台所提供的实验仪器, 通过拖动即可组装 实验装置; 也可以利用化学实验游戏, 在虚拟实验室做实 验。这种实验教学方法, 提供了一个实际的化学实验环境, 对实验中可能会发生的事故不必担心，可以对有毒害、危 险的物质相关的实验进行模拟, 同时还可以展示实验操作 失误引起的后果, 让学生加深印象, 意识到规范性实验的 重要性, 使学生更好的学习化学知识。

例如在学习铜与浓硫酸的反应的化学实验时, 采用模 拟实验的方式进行, 不必担心浓硫酸使用不当对学生造成 的伤害, 以及操作不规范会发生的危险等。但是在教学过 程中, 教师要保证无特殊情况下, 每个人都参与该过程, 在老师的监督下完成这个过程, 而且教师要保持娱乐与教 育的平衡。在中学化学教学中, 实验是主要教学内容, 在 智慧教育理念下的化学实验课, 可以提高实验规范性、拓 展化学视野、增强实验精准度[10]。

\section{5. 线上完成任务, 因材施教}

教师面对一整个班的学生很难做到一对一交流辅导, 所以很难做到真正的因材施教, 让每个学生的疑惑都得到 解答。在智慧教育理念下的教学, 教师根据问题选择合适 的教学平台, 通过智慧教育平台在线发布学习任务, 检测 学生的学习效果。每位同学单独完成, 不存在传统课堂中 的片面的反馈。学习者在学习的过程中会生成大量的数据, 这些大数据是提供个性化的学习诊断、精准推送和多元评 估等个性化自适应学习服务的科学依据[10]。教师通过平 台查看学生的完成情况, 也可以注意到学生的个别问题; 学生可以发布问题, 所有同科目的教师都可以作解答, 学 生也可以相互答疑; 学习平台具有资源智能推送功能, 会 根据记录的学生学习具体情况向学生推送针对性的练习 题, 利于学生查漏补缺。同时教师可在平台中发送相对应 的学习资料, 学生根据自己需求选择所需资料。

通过学生线上完成任务, 教师可以收集、分析动态数 据, 及时调整教学进度、策略, 优化课堂教学, 因材施教, 使化学教学更具有智慧。

\section{6. 使用教育游戏, 综合复习巩固知识}

化学教育游戏, 将娱乐与化学教育相结合。利用教育 游戏来复习巩固化学知识, 可以让学生在复习阶段不枯燥 乏味。教育游戏APP, 有实验类的, 也有概念型的, 例如 化学实验类教育游戏APP“Chemist”。化学教育类游戏很多, 需要教师根据实际需要进行选择, 使用合理。

学生在复习化学概念知识时, 可以采用卡片类的游戏 来帮助学生记忆, 例如对化学设备的相关知识的学习、化 学方程式的记忆等, 可以利用卡片游戏来巩固加深记忆; 在学习酸碱反应时, 可以在新课讲授之后, 使用“化学争 上游”游戏来巩固提升, 根据出牌的游戏规则, 来完成化 学方程式的巩固记忆。

在综合复习巩固知识的时候, 可以采用综合类游戏, 应用较多的是闯关游戏, 例如“化学加油站”游戏, 如果玩
家掌握知识掌握不好或者缺乏, 则无法过关。此类游戏可 以覆盖很多的化学知识, 在教学中可以作为学生的家庭作 业, 激发学生学习兴趣的同时, 有可以增强学生之间你追 我赶的良性竞争。当然, 要注意时间的控制。

\section{5. 结论与展望}

\section{1. 结论}

在新课改的要求下, 将智慧教育理念引入中学化学的 课堂是新课程改革的诉求, 需要引起家长、教师、学校的 重视, 构建新型的化学课堂教学。本研究通过BICOMB2.01 和SPSS25.0进行文献分析智慧教育的发展进行了可视化 分析, 以及智慧教育在化学教学方面的研究进行了整理, 了解智慧教育的发展趋势以及在化学教学方面的发展现 状。

在智慧教育理念下，一个合格的教师，在不断完善个 人教学智慧的同时, 要对整体把握, 智慧教育理念可以体 现在课堂教学的任何一个教学步骤, 不断调整教学策略、 教学设计, 使教学智慧的课堂逐渐形成, 提高教学质量和 效率、有利于教师因材施教, 优化课堂教学, 加深学生对 化学知识的理解和记忆, 如利用网络教学平台实现多元化 评价; 突出学生的主体性, 培养学生的创新思维和创新能 力。

但是, 智慧教育理念的实践, 仍存在许多问题, 在智 慧教育理念下的课堂, 电子设备成为了学生学习过程中必 不可少的辅助物, 学生的自制力不强的情况下, 会影响学 生的专注力; 除此之外, 教师的大数据处理能力也是一个 难题, 这需要不断研究和探索来解决。

总体而言, 目前的智慧教育理念下的化学教学课堂还 存在很多的不足, 教学策略有待于继续研究。

\section{2. 展望}

将智慧教育理念与中学化学教学相结合, 不能随意而 为之, 教师需要不断的探究、实践。目前智慧教育理念下 的中学化学课堂教学策略还存在许多不足之处。希望未来, 学校对于智慧教育的支持力度加强, 创设一个良好的智慧 教学环境, 智慧教育可以与中学化学课堂很好的融合在一 起, 让学生可以在课堂中真切的感受到“听课是一种享受”。 在未来的课堂中, 无意识的形成学生可以智慧学习、教师 可以智慧教学。

\section{参考文献}

[1] 祝智庭,贺斌.智慧教育:教育信息化的新境界 [J].电化教育研 究,2012,33(12):5-13.

[2] 王蓉. 高职化学智慧型课程教学现状分析 [J]. 经济 师,2021(01):210-211.

[3] 祝智庭, 智慧教育新发展: 从翻转课堂到智慧课堂及智慧学 习空间[J].开放教育研究,2016,22(01):18-26+49. 
[4] 中华人民共和国教育部. 教育信息化 2.0 行动计划 [EB/OL].(2018-04-13)[2021-04-15]

http://www.moe.gov.cn/srcsite/A16/s3342/201804/t20180425 334188.html.

[5] 蔡朔,郭慧丽,王勇,刘丰. 智慧环境中化学教学的创新与研 究 [C]. .十三五规划科研成果汇编(第二卷).:十三五规划科 研管理办公室,2017:756-760。

[6] 李强强,吴昌飞,黄国友.智慧环境紧密结合化学课堂教学的 改革实验研究 $[C]$.十三五规划科研成果汇编(第二卷).十三 五规划科研成果汇编(第二卷).十三五规划科研管理办公 室,2017:364-367.

[7] 黄荣怀.智慧教育的三重境界:从环境、模式到体制 [J].现代 远程教育研究,2014(06):3-11.

[8] 杨现民.信息时代智慧教育的内涵与特征 [J]. 中国电化教 育,2014(01):29-34.

[9] 刘伟." 智慧教育"的概念整合及其意义 [J]. 现代教育科 学,2017,(3):16.
[10] 钟慧萍.基于智慧教育理念整合化学实验教学 [J].科学咨询 (科 技·管理),2019,(04):129-130.

[11] 陈琳. 智慧教育创新实践的价值研究 [J]. 中国电化教 育,2015(04):15-19.

[12] 刘颖.浅谈智慧教育在化学课堂中的应用 [J]. 江西化 工,2020(03):123-124.

[13] 姜岩, 吴林. 现代化学教学中智慧课堂与传统课堂的对比及 反思 $[J]$.科教导刊(上旬刊),2019(07):142-143.

[14] 间晓婷, 曾宪龙. 智慧教育在教学中的运用 [J]. 福建电 脑,2021,37(01):160-161.

[15] 郭少玲.智慧课堂背景下优化初中化学课堂教学的策略思 考 $[\mathrm{C}]$.广东教育学会教育现代化专业委员会2020年第三次 学术研讨会论文集.广东教育学会教育现代化专业委员会 2020年第三次学术研讨会论文集.广东晨越教育发展有限 公司,2020:151-154.

[16] 王薇,周宝晗,孙丹,任家强.智慧课堂在分析化学实验中教辅 作用的探索[J].山东化工,2019,48(21):165-166+169. 